\title{
Desain Simulasi Robot Kesetimbangan Dua Roda dengan Kecerdasan Buatan
}

\author{
Ratna Hartayu' ${ }^{1)}$, Santoso $^{2}$, Abraham OUK ${ }^{3)}$, Moh. KM ${ }^{4)}$ \\ ${ }^{122) 344)}$ Program Studi Teknik Elektro, Fakultas Teknik, Universitas 17 Agustus 1945 Surabaya \\ Jl. Semolowaru No.45, Menur Pumpungan, Kec. Sukolilo, Kota SBY, Jawa Timur 60118 \\ 1) rhartayu@untag-sby.ac.id \\ 2) santoso@untag-sby.ac.id \\ 3) abraham@gmail.com \\ 4) mkhilmi@gmail.com
}

\begin{abstract}
Abstrak
Dalam penelitian dijelaskan salah satu metode alternatif analisa kontrol pada robot kesetimbangan dua roda dengan menggunakan progam simulasi. Program simulasi menggunakan software Matlab. Penelitian ini menghasilkan analisa simulasi kontrol, berupa analisa data sensor gyroscope, simulasi PID dan logika fuzzy. Pada simulasi PID nilai kestabilan didapat pada $\mathrm{Kp}=100, \mathrm{Ki}=200, \mathrm{Kd}=10$, hasil analisa data gyroscope didapat nilai minimum pada 0,074616, nilai maksimum 0,110321 , dengan nilai rata-rata 0,092469 , standar deviasi 0,025247 , jumlah data 0,184937 . Penerapan logika fuzzy pada deteksi sudut dan pemberian nilai PWM, menghasilkan data kestabilan nilai konstanta PID. Penelitian ini diharapkan menjadi acuan pemberian nilai kontrol pada robot, dan untuk penelitian berikutnya dapat dikembangkan dengan menambahkan filter komplement atau kalman untuk menghasilkan kestabilan gerak robot.
\end{abstract}

Kata kunci: simulasi, kontrol, PID, fuzzy

\begin{abstract}
In this study, an alternative method of control analysis on a two-wheeled equilibrium robot is described using a simulation program. Simulation program using Matlab software. This study produces a control simulation analysis, in the form of gyroscope sensor data analysis, PID simulation and fuzzy logic. In the PID simulation, the stability value was obtained at $K p=100, K i$ $=200, K d=10$, the results of the gyroscope data analysis obtained a minimum value of 0.074616, a maximum value of 0.110321, with an average value of 0.092469, standard deviation of 0, 025247, the amount of data 0.184937. The application of fuzzy logic to angle detection and PWM value assignment results in the stability of the PID constant value. This research is expected to be a reference for giving control values to the robot, and for further research it can be developed by adding a complementary filter or kalman to produce the stability of the robot's motion.
\end{abstract}

Keywords: simulation, control, PID, fuzzy

\section{PENDAHULUAN}

Perkembangan teknologi robotika telah membuat kualitas kehidupan manusia semakin tinggi. Saat ini perkembangan teknologi robotika telah mampu meningkatkan kualitas maupun kuantitas produksi diberbagai industri [1], [2]. Teknologi robotika juga telah menjangkau sisi hiburan dan pendidikan bagi manusia. Salah satu cara menambah tingkat kecerdasan sebuah robot adalah dengan menambah sensor, metode kontrol bahkan memberikan kecerdasan buatan pada robot tersebut, Robot yang memiliki kecerdasan Salah satunya adalah self balancing robot [3]-[6]. balance robot (robot penyeimbang) merupakan suatu robot yang memiliki dua buah roda disisi kanan dan kirinya yang tidak akan seimbang apabila tanpa adanya kontroler. Balance robot ini merupakan pengembangan dari model pendulum terbalik (inverted pendulum) yang diletakkan di atas kereta beroda[7], [8]. 
Menyeimbangkan robot beroda dua memerlukan suatu perangkaian hardware yang baik dan metode kontrol handal untuk mempertahankan posisi robot dalam keadaan tegak lurus terhadap permukaan bumi. Konsep balance robot ini telah digunakan sebagai alat transportasi yang bernama segway [9].

\section{TINJAUAN PUSTAKA}

\subsection{Pendulum Terbalik}

Robot kesetimbangan menerapkan model pendulum terbalik, dengan kemampuan mempertahankan kedudukan tegak setimbang terhadap suatu objek [7], [10]. Proses kesetimbangan biasanya di sebut juga kontrol stabilitas [11]. Dua roda yang di letakan pada dasar permukaan dan memungkinkan badan robot untuk mempertahankan posisi tegak dan bergerak kearah maju, mundur, berputar dalam upaya menjaga pusat massa di atas as roda [10].

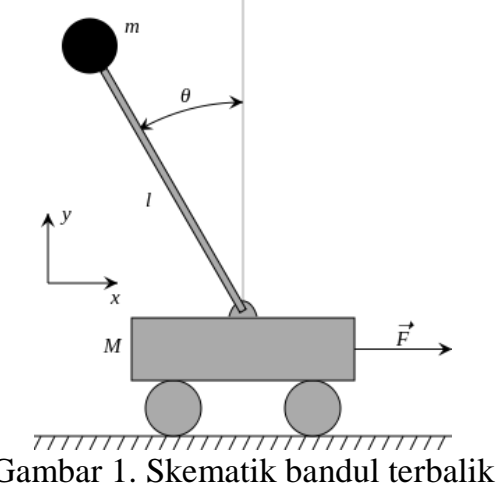

Akibat dari gaya gravitasi bumi, sebuah inverted pendulum yang pada mulanya tegak lurus maka mulai membentuk sudut kemiringan sebesar theta $(\theta)$ dan lama kelamaan akan jatuh. Oleh karena itu, dalam menjaga dan mempertahankan posisi pendulum pada suatu titik maka diperlukan sebuah aksi gaya yang dapat menahan pergerakan pendulum. Cara yang digunakan untuk menghasilkan gaya tersebut adalah dengan cara membuat kereta maju searah sesuai dengan arah kemana pendulum tersebut akan jatuh [12].

\subsection{Kinematik Robot Roda Dua}

Dalam hal robot roda dua, seperti yang disajikan pada Gambar 2, setiap roda dikendalikan oleh motor independen XG dan YG mewakili kerangka global, sedangkan XL dan YL mewakili kerangka lokal. Kecepatan robot ditentukan oleh kecepatan linear $V_{\text {robot }}(t)$ dan kecepatan sudut $\omega_{\text {robot }}(t)$, yang merupakan fungsi dari kecepatan linear dan sudut setiap roda $\omega_{i}(t)$ dan jarak L antara dua roda, $V_{r}(t), \omega_{r}(t)$ adalah kecepatan linier dan sudut dari roda kanan, $V_{l}(t), \omega_{l}(t)$ adalah kecepatan linier dan sudut dari roda kiri, $\theta$ adalah orientasi robot dan $\left(r_{l} r_{r}\right)$ adalah jari-jari roda kiri dan kanan [13].

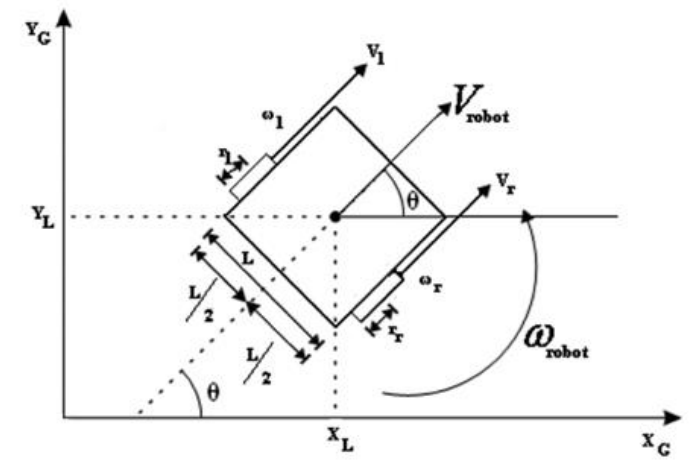

Gambar 2. Kinematik robot roda dua

Kecepatan linier dari setiap roda ditentukan oleh hubungan antara kecepatan sudut dan jarijari roda [14]. 
$V_{r}(t)=\omega_{r}(t) r_{r}, V_{l}(t)=\omega_{l}(t) r_{l}$

Kecepatan robot terdiri dari pusat kecepatan linier massa dan kecepatan sudut yang dihasilkan oleh perbedaan antara dua roda.

$V_{l}(t)=V_{\text {robot }}(t)-\left(\frac{L}{2}\right) \omega_{\text {robot }}(t), V_{r}(t)=V_{\text {robot }}(t)+\left(\frac{L}{2}\right) \omega_{\text {robot }}(t)$

\subsection{Logika Fuzzy}

Fuzzy Logic merupakan kecerdasan buatan yang pertama kali dipublikasikan oleh Prof.Dr. Lotfi Zadeh yang berasal dari Pakistan. Melalui fuzzy logic sistem dapat membuat keputusan sendiri dan terkesan seperti memiliki perasaan, karena memiliki keputusan lain selain iya (logika 1) dan tidak (logika 0). Logika Fuzzy adalah suatu cara memetakan ruang masukan ke dalam ruang keluaran, dengan nilai terus menerus [15], [16]. Fuzzy dinyatakan dalam derajat keanggotaan dan derajat kebenaran. Oleh sebab itu sesuatu dapat dikatakan sebagian benar dan sebagian salah pada waktu yang sama. Dalam logika fuzzy terdapat fuzzifikasi, evaluasi aturan (inference) berdasarkan aturan dasar (rule base), dan defuzzifikasi [17], [18]. Logika fuzzy memiliki logika dengan derajat keanggotaan diantara 0 dan 1, dengan demikian, variabel dalam logika fuzzy dideskripsikan dalam bentuk himpunan fuzzy, diantaranya dalam bentuk segitiga, trapezoidal, Gaussian, Gaussian-bell dan sigmoid.

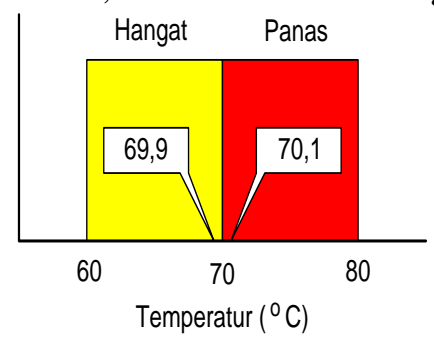

Logika Boolean

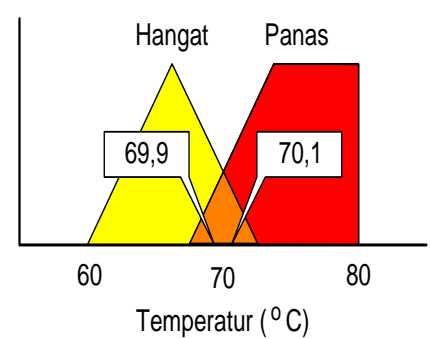

Logika Fuzzy

Gambar 3. Perbedaan antara Logika Boolean dan Logika Fuzzy

\section{METODE PENELITIAN}

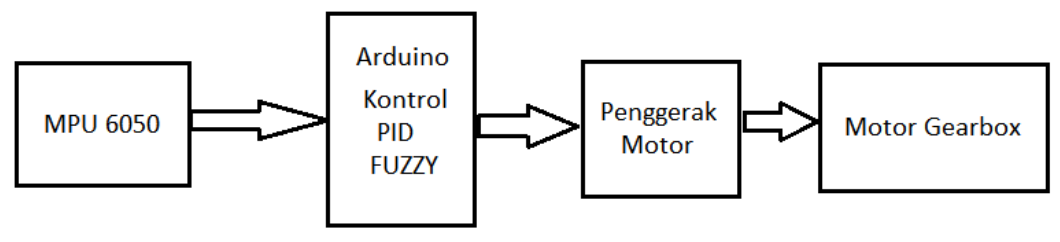

Gambar 4. Blok diagram robot kesetimbangan

Desain rancangan usulan sistem diperlihatkan pada gambar 4. Kendali PID adalah kendali utama yang digunakan pada sistem ini. Parameter masukan utama yang digunakan dalam kendali PID adalah nilai error atau selisih nilai luaran sistem (variable proses) dengan nilai yang diharapkan (set point) [19]. Penambahan kontrol Fuzzy diharapkan akan membantu meningkatkan performa robot kesetimbangan. Dengan penambahan logika fuzzy untuk besaran nilai koefisien dari PID dan dikombinasikan dengan setpoint dari nilai data sensor, akan didapat error dan selisih error, untuk digunakan sebagai nilai input logika fuzzy, hasil kendali akan diumpankan ke kontroller untuk kemudian menghasilkan PWM, nilai dari PWM akan mengendalikan gerakan motor DC [5], [20]. 


\subsection{Robot Setimbang Dua Roda}

Desain robot kesetimbangan dibangun dengan menggunakan dua roda, badan robot terbuat dari acrilyc, kontroller Arduino diletakkan diantara dua roda, rangkaian pendukung ditata untuk menghasilkan tekanan yang setimbang diantara dua roda, rangkaian sensor diletakkan diatas dari robot, guna menghasilkan daya perubahan yang maksimal, diterima oleh Arduino sebagai input data (posisi) diolah dalam logika fuzzy dan PID, untuk kemudian di umpankan ke rangkaian penggerak motor DC dengan mengontrol PWM dijaga konstan sesuai dengan seting nilai yang dikehendaki, pada tampilan LCD akan ditampilkan koefisien, perubahan posisi x, y, z [7], [21]-[23].

\section{PEMBAHASAN}

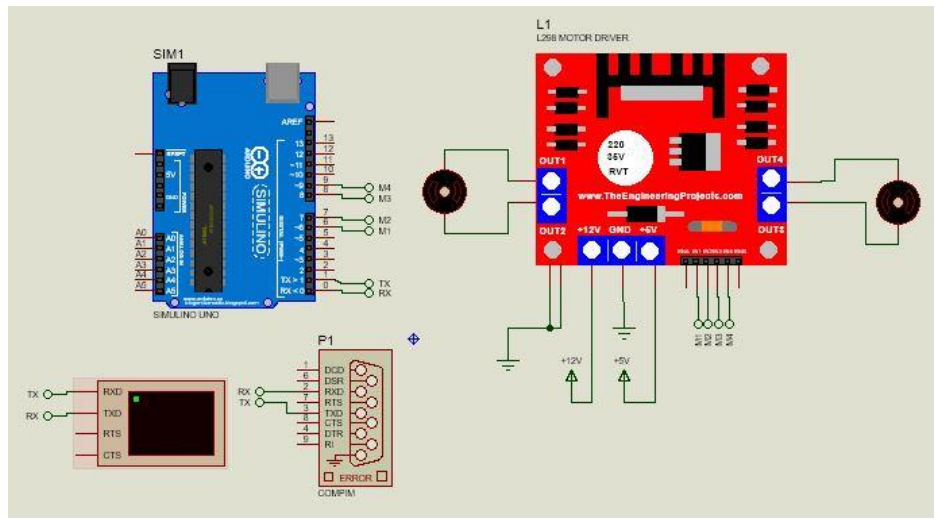

Gambar 5. Simulasi kendali motor

Memakai dua buah motor, sebuah kendali motor L298, arduino uno, virtual serial (compin), dan virtual terminal, perangkat lunak dibangun pada IDE Arduino, simulasi dilakukan dengan mengatur pin $\mathrm{IN} 1=0, \mathrm{IN} 2=1, \mathrm{IN} 3=0, \mathrm{IN} 4=1, \mathrm{ENA}=1, \mathrm{ENB}=1$, kecepatan motor diatur dengan mengatur nilai ENA, ENB dari nilai terendah 0 hingga nilai tertinggi 255 [3], [24].

\subsection{Simulasi PID}

Kendali PID akan menghasilkan respon yang dipengaruhi oleh parameter Kp, Ki dan Kd [5], [7]. Pengujian dilakukan dengan mengubah ubah parameter dan memperhatikan hasil pergerakan robot, didapat nilai dan bentuk sinyal sebagai berikut:

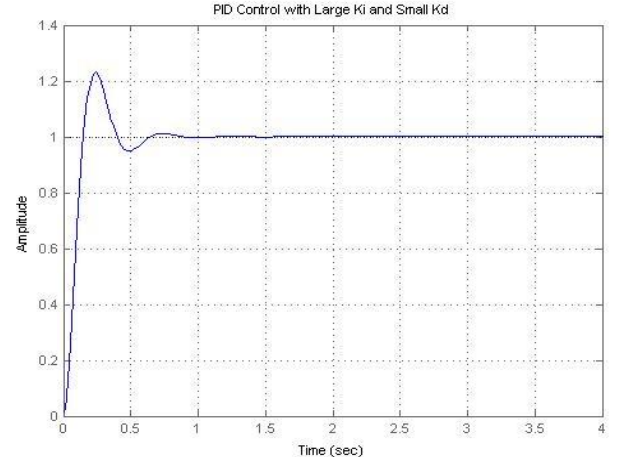

(a)

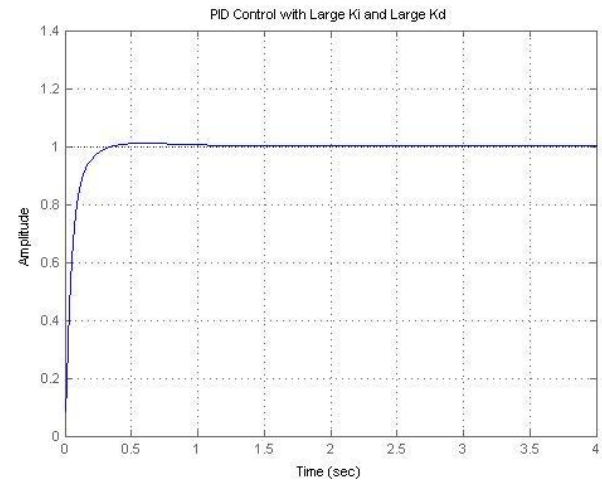

(b)

Gambar 6. (a) $\mathrm{Kp}=100, \mathrm{Ki}=200, \mathrm{Kd}=1$, (b) $\mathrm{Kp}=100, \mathrm{Ki}=200, \mathrm{Kd}=10$

Gambar 6 (b) menunjukkan grapik respon langkah (step response) memiliki nilai yang panjang untuk stabil, hal ini dikarenakan nilai penguatan integral kecil (Ki=Kecil), sehingga membutuhkan waktu lama untuk aksi penyatuan dan mengurangi kesalahan kondisi tetap, dengan penambahan nilai Ki proses tersebut dapat dipercepat, gambar 5(a). Dengan penambahan nilai Ki, 
kesalahan kondisi tetap dapat dikurangi lebih cepat dari sebelumnya, namun juga meningkatkan lonjakan, dengan penambahan nilai Kd akan mengurangi lonjakan, terlihat pada gambar 5(b).

\subsection{Simulasi Logika Fuzzy}

Kontrol fuzzy akan menghasilkan nilai akhir sesuai dengan nilai yang sudah ditentukan, dalam penelitian ini nilai sudut didapatkan dari sensor IMU MPU6050 [8, p. 605].

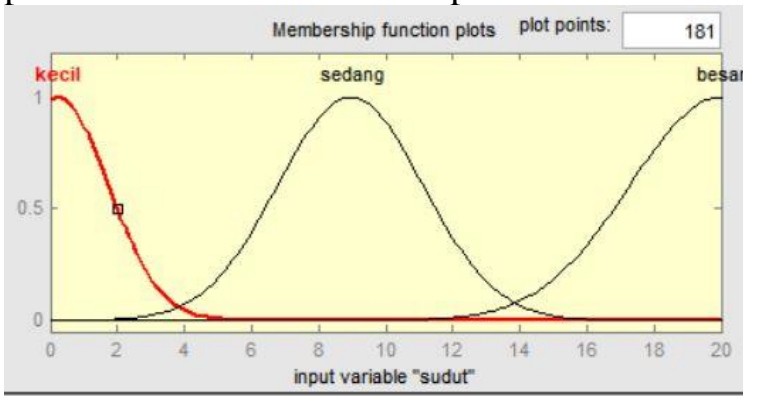

(a)

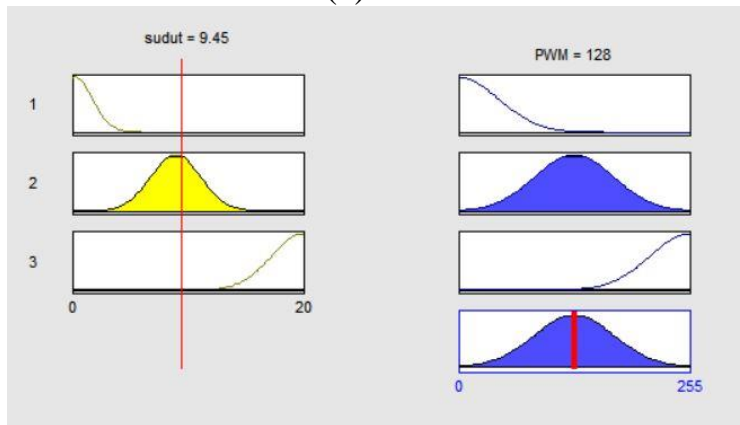

(c)

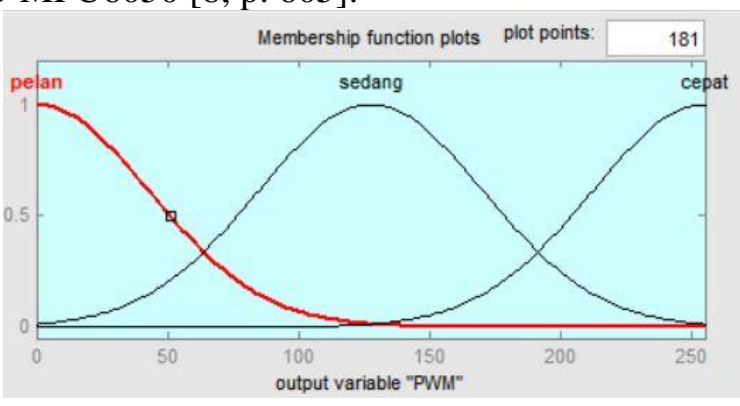

(b)

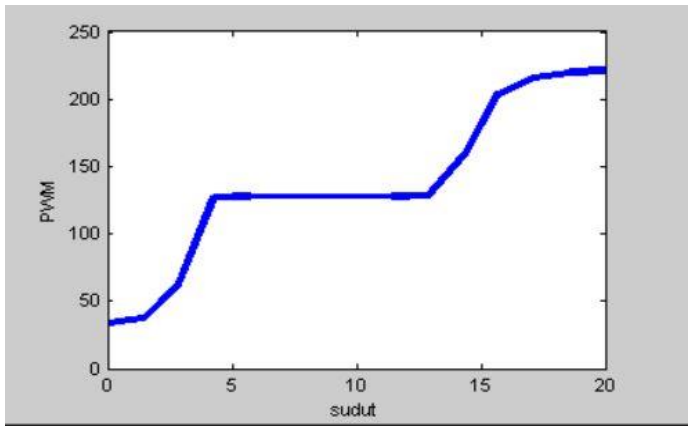

(d)

Gambar 7. (a) Fungsi keanggotaan masukan perubahan sudut, (b) Fungsi keanggotaan keluaran PWM, (c)

Korelasi perubahan sudut terhadap nilai PWM, (d) Grafik perubahan PWM terhadap perubahan sudut

Dari gambar 7 (d) terlihat peningkatan nilai pwm seiring dengan meningkatnya perubahan sudut, nilai pwm $0-120$, pada pergerakan sudut antara $0-5$ derajat, pwm stabil pada 130 , pada pergerakan sudut 4,7- 13 derajat, pwm semakin membesar pada perubahan sudut antara 14-20 derajat.

\subsection{Simulasi Gyroscope}

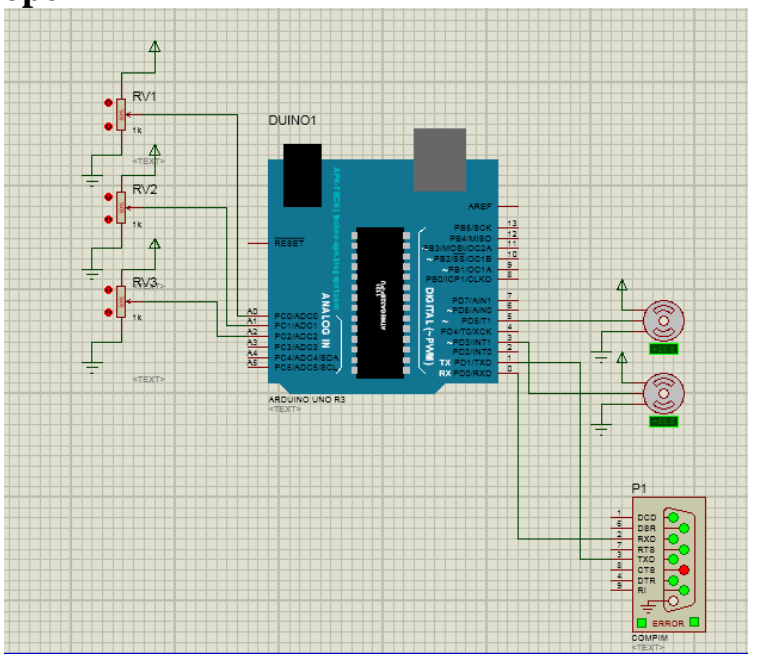

Gambar 8. Rangkaian simulasi sensor Gyroscope pada proteus

Simulasi dibuat dengan menggunakan program proteus, dengan mensimulasikan tiga sinyal dari sensor gyro dengan tiga buah resistor variabel, dan dihubungkan ke A0, A1, dan A2 dari 
Arduino, seperti pada gambar 8. Pengujian juga dilakukan dengan menguji data dari sensor gyroscope. Nilai data diterima diteruskan ke Matlab disimpan dan plot sinyal [8], [25].

Tabel 1. Data Gyroscope

\begin{tabular}{cccc}
\hline No & Gyr_X & Gyr_Y & Gyr_Z \\
\hline 1 & 0,403176 & 0,074616 & 0,263673 \\
2 & 0,388643 & 0,128746 & 0,361635 \\
3 & 0,359002 & 0,134697 & 0,396425 \\
4 & 0,329591 & 0,136528 & 0,388643 \\
5 & 0,294801 & 0,172234 & 0,385667 \\
6 & 0,300866 & 0,182191 & 0,379945 \\
7 & 0,300981 & 0,175553 & 0,365754 \\
8 & 0,256806 & 0,178643 & 0,357514 \\
9 & 0,231743 & 0,159989 & 0,310364 \\
10 & 0,234375 & 0,13607 & 0,241242 \\
11 & 0,248223 & 0,089607 & 0,147858 \\
12 & 0,271454 & 0,043602 & 0,057678 \\
13 & 0,395051 & $-0,018654$ & $-0,050697$ \\
14 & 0,62588 & $-0,06958$ & $-0,164796$ \\
15 & 0,856026 & $-0,11902$ & $-0,22053$ \\
16 & 0,955364 & $-0,192606$ & $-0,203707$ \\
\hline
\end{tabular}

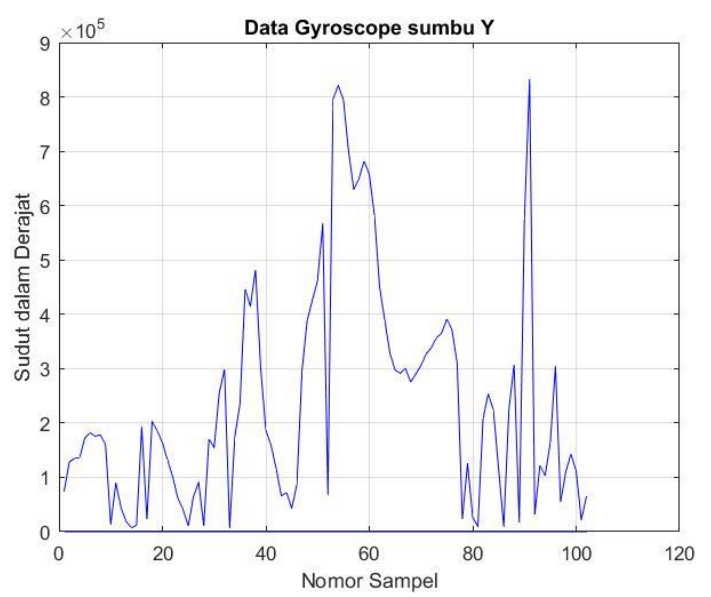

Gambar 9. Plot sinyal data gyroscope

Dari hasil simulasi didapat nilai minimum pada 0,074616 , nilai maksimum 0,110321 , nilai rata-rata 0,092469, standar deviasi 0,025247 , jumlah data (sum) 0,184937 , mean 0,092469 .

\section{KESIMPULAN}

Berdasarkan hasil simulasi diperoleh nilai PID kestabilan pada $\mathrm{Kp}=100, \mathrm{Ki}=200, \mathrm{Kd}=10$, hasil analisa data gyroscope didapat nilai minimum pada 0,074616 , nilai maksimum 0,110321 , dengan nilai rata-rata 0,092469 , standar deviasi 0,025247 , jumlah data 0,184937 . Penerapan logika fuzzy pada deteksi sudut dan pemberian nilai PWM, menghasilkan data kestabilan nilai konstanta PID. Penelitian ini diharapkan menjadi acuan pemberian nilai kontrol pada robot, dan untuk penelitian berikutnya dapat dikembangkan dengan menambahkan filter komplement atau kalman untuk menghasilkan kestabilan gerak robot. 


\section{UCAPAN TERIMA KASIH}

Terimakasih kepada Universitas 17 Agustus 1945 Surabaya, telah membiayai penelitian ini.

\section{DAFTAR PUSTAKA}

[1] M. H. Weik, 'manipulating industrial robot', in Computer Science and Communications Dictionary, Boston, MA: Springer US, 2000, pp. 972-972.

[2] V. D. Tugaev and V. Ya. Kulibaba, 'Introduction of an industrial robot in a machine shop', Metallurgist, vol. 30, no. 10, pp. 380-381, Oct. 1986, doi: 10.1007/BF00741414.

[3] P. Frankovský, L. Dominik, A. Gmiterko, I. Virgala, P. Kurylo, and O. Perminova, 'Modeling of Two-Wheeled Self-Balancing Robot Driven by DC Gearmotors', Int. J. Appl. Mech. Eng., vol. 22, no. 3, pp. 739-747, Aug. 2017, doi: 10.1515/ijame-2017-0046.

[4] C. Gonzalez, I. Alvarado, and D. M. L. Peña, 'Low cost two-wheels self-balancing robot for control education', IFAC-Pap., vol. 50, no. 1, pp. 9174-9179, Jul. 2017, doi: 10.1016/j.ifacol.2017.08.1729.

[5] T. A. Mai, T. S. Dang, D. N. Anisimov, and E. Fedorova, 'Fuzzy-PID Controller for Two Wheels Balancing Robot Based on STM32 Microcontroller', in 2019 International Conference on Engineering Technologies and Computer Science (EnT), Moscow, Russia, Mar. 2019, pp. 20-24, doi: 10.1109/EnT.2019.00009.

[6] S. Santoso and S. Mursyid, 'KONTROL PROPORTIONAL INTEGRAL (PI) PADA ROBOT LINE FOLLOWER', J. Sains Dan Inform., vol. 1, no. 1, pp. 10-10, Sep. 2017.

[7] A. Odry and R. Fuller, 'Comparison of Optimized PID and Fuzzy Control Strategies on a Mobile Pendulum Robot', in 2018 IEEE 12th International Symposium on Applied Computational Intelligence and Informatics (SACI), Timisoara, May 2018, pp. 000207000212, doi: 10.1109/SACI.2018.8440947.

[8] Y. Xin, B. Xu, H. Xin, J. Xu, and L. Hu, 'The Computer Simulation and Real-Time Control for the Inverted Pendulum System Based on PID', in Communication Systems and Information Technology, vol. 100, M. Ma, Ed. Berlin, Heidelberg: Springer Berlin Heidelberg, 2011, pp. 729-736.

[9] H. Yun, J. Bang, J. Kim, and J. Lee, 'High speed segway control with series elastic actuator for driving stability improvement', J. Mech. Sci. Technol., vol. 33, no. 11, pp. 5449-5459, Nov. 2019, doi: 10.1007/s12206-019-1039-x.

[10] C.-H. Huang, W.-J. Wang, and C.-H. Chiu, 'Design and Implementation of Fuzzy Control on a Two-Wheel Inverted Pendulum', IEEE Trans. Ind. Electron., vol. 58, no. 7, pp. 29883001, Jul. 2011, doi: 10.1109/TIE.2010.2069076.

[11] Ş. Yıldırım and E. Arslan, 'ODE (Open Dynamics Engine) based stability control algorithm for six legged robot', Measurement, vol. 124, pp. 367-377, Aug. 2018, doi: 10.1016/j.measurement.2018.03.057.

[12] F. Fahmizal, G. Setyawan, M. Arrofiq, and A. Mayub, 'Logika Fuzzy Pada Robot Inverted Pendulum Beroda Dua', J. Teknol. Inf. Dan Ilmu Komput., vol. 4, no. 4, p. 244, Dec. 2017, doi: $10.25126 /$ jtiik.201744484.

[13] S. Noga, 'Kinematics and dynamics of some selected two-wheeled mobile robots', Arch. Civ. Mech. Eng., vol. 6, no. 3, pp. 55-70, Jan. 2006, doi: 10.1016/S1644-9665(12)602416.

[14] A. Chhotray, M. K. Pradhan, K. K. Pandey, and D. R. Parhi, 'Kinematic Analysis of a TwoWheeled Self-Balancing Mobile Robot', p. 8.

[15] L. A. Zadeh, 'Fuzzy logic—a personal perspective', Fuzzy Sets Syst., vol. 281, pp. 4-20, Dec. 2015, doi: 10.1016/j.fss.2015.05.009.

[16] L. A. Zadeh, 'Toward extended fuzzy logic—A first step', Fuzzy Sets Syst., vol. 160, no. 21, pp. 3175-3181, Nov. 2009, doi: 10.1016/j.fss.2009.04.009.

[17] M. K. Medynskaya, 'Fuzzy set theory. The concept of fuzzy sets', in 2015 XVIII International Conference on Soft Computing and Measurements (SCM), St. Petersburg, Russia, May 2015, pp. 30-31, doi: 10.1109/SCM.2015.7190402. 
[18] K. Sadegh-Zadeh, 'Advances in fuzzy theory', Artif. Intell. Med., vol. 15, no. 3, pp. 309323, Mar. 1999, doi: 10.1016/S0933-3657(98)00060-8.

[19] R. Bimarta, A. E. Putra, and A. Dharmawan, 'Balancing Robot Menggunakan Metode Kendali Proporsional Integral Derivatif’, IJEIS Indones. J. Electron. Instrum. Syst., vol. 5, no. 1, p. 89, May 2015, doi: 10.22146/ijeis.7157.

[20] G.-R. Yu, Y.-K. Leu, and H.-T. Huang, 'PSO-based fuzzy control of a self-balancing twowheeled robot', in 2017 Joint 17th World Congress of International Fuzzy Systems Association and 9th International Conference on Soft Computing and Intelligent Systems (IFSA-SCIS), Otsu, Japan, Jun. 2017, pp. 1-5, doi: 10.1109/IFSA-SCIS.2017.8023296.

[21] N. Cameron, 'Robot Car', in Arduino Applied, Berkeley, CA: Apress, 2019, pp. 467-497.

[22] T. Anitha, G. Gopu, M. Nagarajapandian, and P. A. M. Devan, 'Hybrid Fuzzy PID Controller for Pressure Process Control Application', in 2019 IEEE Student Conference on Research and Development (SCOReD), Bandar Seri Iskandar, Malaysia, Oct. 2019, pp. 129-133, doi: 10.1109/SCORED.2019.8896276.

[23] T. Pan and Y. Zhu, 'Using Sensors with the Arduino', in Designing Embedded Systems with Arduino, Singapore: Springer Singapore, 2018, pp. 45-100.

[24] C.-F. Hsu and B.-K. Lee, 'FPGA-based adaptive PID control of a DC motor driver via sliding-mode approach', Expert Syst. Appl., vol. 38, no. 9, pp. 11866-11872, Sep. 2011, doi: 10.1016/j.eswa.2011.02.185.

[25] I. Kecskés and P. Odry, 'Optimization of PI and Fuzzy-PI Controllers on Simulation Model of Szabad(ka)-II Walking Robot', Int. J. Adv. Robot. Syst., vol. 11, no. 11, p. 186, Nov. 2014, doi: 10.5772/59102.

\section{Biodata Penulis}

Ir.Ratna Hartayu,MT, lahir di Lumajang pada tahun 1965. Penulis Pertama memperoleh gelar Ir. Jurusan Teknik Fisika di Institut Teknologi Sepuluh Nopember Surabaya pada Tahun 1989. Kemudian melanjutkan pendidikan S2 jurusan Teknik Elektro di Institut Teknologi Sepuluh Nopember Surabaya dan lulus Tahun 1999. Konsentrasi penelitian penulis pertama yaitu Sistem Pengaturan dan Kewirausahaan. Saat ini penulis adalah salah satu dosen di Jurusan Teknik Elektro pada Universitas 17 Agustus 1945 Surabaya.

Santoso ST.,MT, lahir di Jembrana-Bali pada tahun 1973. Penulis kedua memperoleh gelar ST Jurusan Teknik Elektronika di Institut Teknologi Nasional Malang pada Tahun 1997. Kemudian melanjutkan pendidikan S2 di Institut Teknologi Sepuluh Nopember Surabaya dan lulus Tahun 2012. Konsentrasi penelitian penulis kedua yaitu bidang Artificial Intellience dan Robotika. Saat ini penulis adalah salah satu dosen di Jurusan Teknik Elektro pada Universitas 17 Agustus 1945 Surabaya.

Abraham Octorio Umbu Kaleka, lahir pada tanggal 12 bulan agustus di Magetan - Jawa Timur pada tahun 1998. saat ini penulis ketiga masih menempuh pendidikan di Universitas 17 Agustus 1945 Surabaya mulai dari tahun 2016. konsentrasi penelitian penulis ketiga yaitu di bidang Analisa Sensor.

Moh. Khilmi Musakhol, ST., lahir di Lamongan-Jawa Timur pada 17 Oktober 1997. Penulis keempat memperoleh gelar ST Jurusan Teknik Elektro di Universitas 17 Agustus 1945 Surabaya pada Tahun 2020. Saat ini penulis keempat bekerja dibidang teknik elektro. 